\title{
Efeito da adição de farinha de linhaça à dieta sobre a concentração de colesterol e ácidos graxos em camarões
}

\author{
[The effect of feed added of linseed on cholesterol and fatty acids in shrimp] \\ F.L. Santos ${ }^{1}$, V.B. Azeredo ${ }^{2}$, C.T. Andrade ${ }^{3}$, I.P. Marques ${ }^{4}$, G.A. Romeiro ${ }^{4}$, K.G.L. Araújo ${ }^{5 *}$ \\ ${ }^{1}$ Aluno de pós-graduação - Universidade Federal Fluminense - Niterói, RJ \\ ${ }^{2}$ Faculdade de Nutrição - Universidade Federal Fluminense - Niterói, RJ \\ ${ }^{3}$ Instituto de Química - Universidade Federal do Rio de Janeiro, RJ \\ ${ }^{4}$ Instituto de Química - Universidade Federal Fluminense - Niterói, RJ \\ ${ }^{5}$ Faculdade de Farmácia - Universidade Federal Fluminense - Niterói, RJ
}

\begin{abstract}
RESUMO
Avaliou-se a expressão de ácidos graxos, macronutrientes e colesterol de camarões-da-malásia alimentados com dieta adicionada de sementes de linhaça. Quinhentos camarões foram distribuídos em dois grupos e alimentados durante 90 dias com dietas contendo: 1) lipídeo proveniente de linhaça e 2)

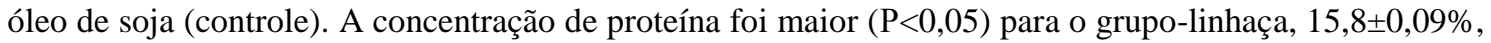
em relação ao grupo-controle, $15,2 \pm 0,04 \%$. O peso corporal também se apresentou maior no grupolinhaça, $1,38 \pm 0,93 \mathrm{~g}$, em relação ao grupo-controle, $0,93 \pm 0,48 \mathrm{~g}$. O grupo-linhaça apresentou teor de colesterol de $120,8 \pm 23,9 \mathrm{mg} / 100 \mathrm{~g}$ e o grupo-controle, $130,2 \pm 13,9 \mathrm{mg} / 100 \mathrm{~g}$, porém sem diferença estatística significativa. Em relação ao perfil lipídico, a suplementação da dieta com linhaça influenciou a incorporação do ácido oleico $(\mathrm{C} 18: 1, \omega-9)$ e melhorou a relação $\omega-6 / \omega-3$ na carne do camarão $(\mathrm{P}<0,05)$. Concluiu-se que a adição de linhaça à ração promoveu importantes modificações na qualidade nutricional dos tecidos do camarão.
\end{abstract}

Palavras-chave: camarão, macronutrientes, linhaça, colesterol, ácidos graxos

\begin{abstract}
The aim of the present study was to analyze the chemical composition of shrimp fed with a diet added of linseed flour. Five hundred post larvae shrimp were divided into two groups: a linseed group fed with a diet based on casein complemented with linseed and a control group, fed a diet without linseed flour. The cholesterol content for the linseed group was $120.8 \pm 23.9 \mathrm{mg} / 100 \mathrm{~g}$ while for the control group it was $130.2 \pm 13.9 \mathrm{mg} / 100 \mathrm{~g}$. However, the protein content of $15.8 \pm 0.09 \%$ and the body weight of $1.38 \pm 0.93 \mathrm{~g}$ for the linseed group were higher than for the control group. It was concluded that the addition of linseed to the diet seems to increase the protein, weight and oleic acid (C18:1, $\omega-9)$ in the shrimp tissue. The ratio of polyunsaturated fatty acids/saturated fatty acids and $\omega-6 / \omega-3$ for the linseed group was more suitable than for the control group.
\end{abstract}

Keywords: shrimp, macronutriens, linseed, cholesterol, fatty acids

\section{INTRODUÇÃO}

A alimentação é considerada um dos principais fatores determinantes da composição do tecido muscular, principalmente da qualidade de ácidos graxos dos lipídeos dos tecidos animais (Almeida

Recebido em 27 de junho de 2012

Aceito em 20 de setembro de 2012

*Autor para correspondência (corresponding author)

E-mail: klima@vm.uff.br e Bueno Franco, 2006). Entretanto, deve-se considerar que são vários os fatores que determinam a composição química de uma espécie de pescado. Entre estes, pode-se citar genética, sexo, tipo e época da desova, além de fatores ambientais relacionados com variações em seu habitat, formas de criação e alimentação (Zenebe et al., 1998; Moreira et al., 2001). 
A composição em ácidos graxos do corpo dos animais reflete, então, a composição destes nos alimentos consumidos, sendo conferido a tais nutrientes importante papel nos tecidos biológicos, relacionado à sua função estrutural nas membranas celulares, influenciando sua permeabilidade, bem como à sua função reguladora na atividade enzima-membrana e no transporte e no metabolismo do colesterol, além da produção de diferentes prostaglandinas, tromboxanos e leucotrienos (Mckensie, 2001). Tem sido conferido aos ácidos graxos da série $\omega$ 3, o eicosapentaenóico (EPA) e o docosahexaenóico (DHA), ação preventiva e terapêutica para doenças cardiovasculares, hipertensão e inflamações em geral (Suárez-Mahecha et al., 2002; Almeida e Bueno Franco, 2006).

Estudos em animais têm demonstrado que o fornecimento de rações suplementadas com fonte de ácidos graxos poli-insaturados de configuração ômega três $(\omega-3)$, como o óleo de linhaça, aumenta a incorporação do conteúdo desse tipo de lipídeo no organismo. Esses estudos foram realizados com o objetivo de modificar o perfil lipídico de tecidos de diferentes animais, como a tilápia-do-nilo (Hayashi et al., 2000; Visentainer et al., 2000,

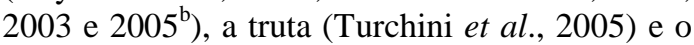
escargot francês (Hayashi et al., 2004), e mostraram que, ao variar a fonte de lipídeos da dieta, foi possível obter um produto final com elevado teor de ácidos graxos essenciais, principalmente da série $\omega-3$ e $\omega-6$ (Hayashi et al., 2004).

O camarão é um fruto do mar que apresenta alta concentração de ácidos graxos poli-insaturados (AGPI) (Furuya et al., 2006), mas sua concentração em colesterol é também considerada elevada (Bragagnolo e RodriguezAmaya, 2001; Santos et al., 2007). No entanto, alguns pesquisadores sugerem a possibilidade de que a alta concentração de AGPI possa anular os efeitos nocivos do colesterol no organismo humano (Bragagnolo e Rodriguez-Amaya, 2001). Assim, o presente estudo objetiva avaliar o efeito da dieta adicionada de farinha de semente de linhaça sobre o teor de colesterol e ácidos graxos em tecidos de camarão-d'águadoce (Macrobrachium rosenbergii).

\section{MATERIAL E MÉTODOS}

O experimento foi realizado em Itaipuaçu, município de Maricá, no estado do Rio de Janeiro, entre dezembro de 2007 e fevereiro de 2008. Foram utilizadas 500 pós-larvas de camarão-d'água-doce, com peso médio inicial de $330 \mathrm{mg}$, oriundos da Fazenda Santa Helena, Silva Jardim, RJ. As pós-larvas foram distribuídas em dois grupos e mantidas em diferentes tanques polyfit de mil litros: 1) grupocontrole, alimentado com dieta à base de caseína; 2) grupo-teste, alimentado com dieta à base de farinha de linhaça da marca Erva-Viva e caseína. Cada tanque recebeu oxigenação constante, por meio de bombas elétricas da marca Sarlo Better mod. S300 - $110 \mathrm{~V}$, com capacidade de 280L/h. A limpeza dos tanques foi realizada diariamente, com renovação de $20 \%$ do volume da água. As dietas foram elaboradas segundo as características bromatológicas do Manual de Carcinicultura de Água Doce (SEBRAE/ES, 2005), e os ingredientes utilizados no seu preparo são apresentados na Tab. 1 .

Os ingredientes foram homogeneizados por 10 minutos em batedeira doméstica e, posteriormente, acrescentou-se água fervente para gelatinização do amido e formação de uma massa com textura lisa. Após dar o ponto à massa, esta foi colocada no peletizador para formação de pequenos pellets, distribuídos em tabuleiros e colocados em estufa ventilada a $55^{\circ} \mathrm{C}$ por 22 horas, até obtenção de umidade ao redor de $3 \%$. Na dieta do grupo-linhaça, em virtude da farinha de linhaça já conter lipídeos e fibras em quantidades adequadas, não foi necessário adicionar esses nutrientes. As dietas, dessa forma, mantiveram características normoproteica e normocalórica.

Durante a experimentação, a ração foi ofertada duas vezes ao dia, sendo, na primeira quinzena, na quantidade de $0,1 \mathrm{~g}$ de ração por camarão e, nos dias posteriores, o equivalente a $5 \%$ da biomassa total dos viveiros, de forma equivalente para os dois tratamentos (SEBRAE/ES, 2005). 
Efeito da adição...

Tabela 1. Formulação das dietas em 100g para camarões

\begin{tabular}{|c|c|c|}
\hline Ingrediente & Linhaça (\%) & Controle $(\%)$ \\
\hline Caseína & 31,26 & 38,09 \\
\hline Linhaça $^{1}$ & 22,94 & - \\
\hline Amido & 38,29 & 39,38 \\
\hline Óleo de soja & - & 8,0 \\
\hline Celulose & - & 7,02 \\
\hline BHT & 0,02 & 0,02 \\
\hline Calcário & 2,10 & 2,10 \\
\hline Fosfato bicálcico & 5,30 & 5,30 \\
\hline Suplemento mineral e vitamínico ${ }^{2}$ & 0,4 & 0,4 \\
\hline Vitamina $\mathrm{C}$ & 0,05 & 0,05 \\
\hline Total & 100 & 100 \\
\hline
\end{tabular}

1)Linhaça (Erva-viva); 2) suplemento mineral e vitamínico (níveis de garantia por kg de Premix) (Purina): magnésio 0,4g, manganês $10 \mathrm{mg}$, cobre $50 \mathrm{mg}$, zinco $100 \mathrm{mg}$, iodo $0,3 \mathrm{mg}$, selênio $0,15 \mathrm{mg}$, vit. A 3800UI, vit. D3 $1900 \mathrm{UI}$, vit. E 140UI, vit. K 20mg, ácido fólico $7 \mathrm{mg}$, colina $1400 \mathrm{mg}$, biotina $0,20 \mathrm{mg}$, niacina $130 \mathrm{mg}$, pantotenato de cálcio $40 \mathrm{mg}$, tiamina $15 \mathrm{mg}$, riboflavina 20mg, piridoxina 20mg, vit. B12 20mcg, vit. C $150 \mathrm{mg}$ e monofosfato de ácido ascórbico L $0.05 \mathrm{~g}$.

O peso do camarão foi determinado em balança analítica da marca Sartorius com capacidade máxima de $160 \mathrm{~g}$. Trinta camarões separados de cada grupo nos dias zero, 30, 60 e 90 foram pesados individualmente, de corpo inteiro, para o cálculo da média do peso corporal.

A determinação da concentração de proteínas e lipídeos das amostras foi realizada em triplicata. Devido ao tamanho dos camarões, as análises foram feitas de corpo inteiro, com casca e cabeça. A composição química da farinha de linhaça (média e desvio-padrão) utilizada no experimento é apresentada na Tab. 2.

Tabela 2. Composição química da farinha de linhaça utilizada no experimento $(\mathrm{g} / 100 \mathrm{~g})$ para camarões

\begin{tabular}{c|c} 
Proteína & $23,46 \pm 0,47$ \\
Lipídeo & $34,87 \pm 0,06$ \\
Carboidrato & $1,61 \pm 0,01$ \\
Fibra & $30,64 \pm 0,25$ \\
Cinzas & $3,32 \pm 0,02$ \\
Umidade & $6,10 \pm 0,06$ \\
\hline
\end{tabular}

Durante o experimento, foram coletados de cada grupo aproximadamente $52 \mathrm{~g}$ de camarão aos zero, 30, 60 e 90 dias, para a realização das análises: proteína pelo método de kjeldahl, (Association..., 1995) e lipídeo total pelo método de Bligh-Dyer (1959). Os mesmos métodos foram usados para análises na farinha de linhaça, exceto para o lipídeo total, que foi determinado pelo método de Soxhlet (Association..., 1995), e fibra alimentar, que foi determinada segundo o método de van Soest modificado por Mendez et al. (1985), com determinação quantitativa gravimétrica. O teor de cinzas da linhaça foi determinado segundo as IAL (Instituto ..., 1985) e o carboidrato por meio da diferença entre 100 e o somatório das determinações de umidade, gordura, proteína e cinzas.

Das amostras de lipídeos extraídos do camarão foram feitas saponificação, extração com hexano e diluição do resíduo com $0,5 \mathrm{~mL}$ de isopropanol (Bragagnolo e Rodriguez-Amaya, 2001). O teor de colesterol foi determinado em uma alíquota de $20 \mu \mathrm{L}$ desse extrato, por meio do kit Bioclin Colesterol Monorreagente, após 10 minutos de incubação em banho-maria a $37^{\circ} \mathrm{C}$. As leituras foram feitas em espectrofotômetro (UV1601Visible Spectrophotometer/Shimadzu), no comprimento de onda de $500 \mathrm{~nm}$.

Os ácidos graxos foram determinados por cromatografia gasosa com detector de espectrometria de massas (CG-MS), após hidrólise e metilação, segundo a técnica proposta por Hartman e Lago (1973). Essa análise foi realizada em laboratório de conversão a baixa temperatura (aparelho CG-MS Shimadzu, modelo QP2010). A coluna utilizada foi do tipo capilar de sílica fundida (DB-5MS), com $20 \mathrm{~m}$ de comprimento, $0,18 \mu \mathrm{m}$ de espessura e $0,25 \mu \mathrm{m}$ de diâmetro. $\mathrm{O}$ gás de arraste foi o hélio, com fluxo de $0,4 \mathrm{~mL} /$ minuto. A temperatura inicial da coluna foi de $100^{\circ} \mathrm{C}$ e foi elevada até $295^{\circ} \mathrm{C}$, a uma taxa de $5^{\circ} \mathrm{C} / \mathrm{min}$, por oito minutos. A 
temperatura da fonte de íons foi de $150^{\circ} \mathrm{C}$; do injetor, de $280^{\circ} \mathrm{C}$; e da interface, de $280^{\circ} \mathrm{C}$. O modo de injeção foi splitless, e o intervalo de $\mathrm{m} / \mathrm{z}$ de 20.00 a 800.00 . A quantidade de amostra injetada foi de $1 \mu \mathrm{L}$, dissolvida em diclorometano.

Os diferentes ácidos graxos foram identificados por comparação dos seus espectros de massas com os espectros de padrões pertencentes à biblioteca do equipamento. A relação dos ácidos graxos foi analisada por meio da razão ( / ) entre a área relativa do pico do ácido graxo em questão e a área relativa do ácido palmítico, que se apresentou como o ácido graxo saturado majoritário nas amostras de camarão.

Os resultados foram apresentados por meio da estatística descritiva, como média e desviopadrão. Utilizou-se o teste $t$ não pareado para comparação entre as médias dos dois grupos em diferentes momentos, 30, 60, e 90 dias de experimento - e análise de variância com pósteste Tukey-Kramer para comparar as médias dentro de cada grupo ao longo do tempo. Foi aceito um nível de significância de $5 \%$, e as análises foram realizadas por meio do programa GraphPad InStat.

\section{RESULTADOS E DISCUSSÃO}

Na Tab. 3, é apresentada a composição química dos camarões submetidos aos diferentes tratamentos. Ao final do experimento, o grupolinhaça apresentou valor médio de proteína mais elevado $(\mathrm{P}<0,05)$ do que o grupo-controle, representando um aumento ao redor de 3,4\% para o grupo-controle e de $7,4 \%$ para o grupolinhaça (Tab. 3). Valor similar foi relatado por Santos et al. (2007) em estudo com Macrobrachium rosenbergii, $16,0 \mathrm{~g} / 100 \mathrm{~g}$, alimentado durante dois meses com dieta à base de farinha de linhaça. Na literatura, diferentes concentrações de proteínas corporais podem ser observadas em função da espécie estudada, como o citado pela TBCA (Tabela..., 2006), $19,0 \mathrm{~g} / 100 \mathrm{~g}$, em camarões de água salgada, e por Pedrosa e Cozzolino (2001), 10,62 g/100g, em camarões Penaeus brasilienses oriundos do cais do porto de Natal. Dessa forma, o presente estudo evidencia o potencial da ração adicionada de semente de linhaça em elevar a concentração de proteína no camarão $M$. rosenbergii, representando uma rica fonte de proteína para a dieta humana.

Tabela 3. Composição de proteínas e lipídeos dos camarões segundo os tratamentos e os tempos de avaliação (média e desvio-padrão)

\begin{tabular}{clr} 
Grupo - dia & Proteína (\%) & Lipídeo (\%) \\
\hline Grupo-controle & & \\
0 & $14,7 \pm 0,14$ & $7,17 \pm 1,37$ \\
30 & $14,58 \pm 0,26 \mathrm{a}$ & $3,04 \pm 0,35 \mathrm{a}$ \\
60 & $14,6 \pm 0,03 \mathrm{a}$ & $1,97 \pm 0,16 \mathrm{a}$ \\
90 & $15,2 \pm 0,04 \mathrm{a}$ & $2,08 \pm 0,37 \mathrm{a}$ \\
Grupo-linhaça & & \\
30 & $18,9 \pm 0,08 \mathrm{~b}$ & $2,71 \pm 0,08 \mathrm{a}$ \\
60 & $16,9 \pm 0,57 \mathrm{~b}$ & $2,61 \pm 0,11 \mathrm{~b}$ \\
90 & $15,8 \pm 0,09 \mathrm{~b}$ & $2,3 \pm 0,10 \mathrm{a}$ \\
\hline
\end{tabular}

Médias com letras diferentes em cada tempo de experimento apresentam diferença significativa, $(\mathrm{P}<0,05)$, entre os grupos pelo teste $t$ não pareado.

Ao final do experimento, não foi observada diferença significativa entre os grupos em relação às concentrações de lipídeos totais (Tab. 3). Furuya et al. (2006) observaram valores mais baixos de lipídeos $(1,5 \mathrm{~g} / 100 \mathrm{~g})$ ao utilizarem o mesmo método de análise em camarões inteiros da espécie $M$. amazonicum. Outro estudo, realizado com camarão ( $M$. rosenbergii), utilizando diferente método de análise (Association..., 1984), mostrou teor mais baixo de lipídeos totais em músculos de camarões em que foram removidos cabeça, casca, rabo, pernas e intestinos $(1,1 \mathrm{~g} / 100 \mathrm{~g}$; Bragagnolo e Rodriguez-Amaya, 2001). Segundo Bragagnolo e Rodriguez-Amaya (1997), o músculo do camarão contém menos que $1 \%$ de lipídeos totais, porque o depósito de gordura é estocado no hepatopâncreas, localizado na região da cabeça, o que esclarece os resultados baixos de lipídeos totais encontrados.

A concentração de colesterol dos camarões utilizados no experimento é apresentada na Tab. 4. Os teores de colesterol não diferiram entre os grupos, mas dentro dos grupos, ao longo do tratamento, apresentaram diferença significativa $(\mathrm{P}<0,05)$ entre zero e 90 dias de experimento. Os teores de colesterol não apresentaram diferença significativa entre os grupos ao final do experimento. Os teores de colesterol apresentaram-se próximos ao relatado por Santos et al. (2007) (115,7mg/100g) e abaixo dos citados por Bragagnolo e Rodriguez-Amaya 
(1997; 2001) em camarões Penaeus brasiliensis e em camarões-da-malásia (139mg/100g; $136 \mathrm{mg} / 100 \mathrm{~g})$, respectivamente.

Tabela 4. Teor de colesterol dos camarões segundo os tratamentos e os tempos de avaliação (média e desvio-padrão)

\begin{tabular}{cc}
\hline Grupo - dia & $\begin{array}{l}\text { Colesterol } \\
(\mathrm{mg} / 100 \mathrm{~g})\end{array}$ \\
\hline Grupo-controle & \\
\hline 0 & $261,0 \pm 15,2^{*}$ \\
30 & $135,5 \pm 24,9 \mathrm{a}$ \\
60 & $119,6 \pm 23,4 \mathrm{a}$ \\
90 & $130,2 \pm 13,9 \mathrm{a}^{*}$ \\
Grupo-linhaça & $133,4 \pm 0,46 \mathrm{a}$ \\
30 & $133,4 \pm 0,59 \mathrm{a}$ \\
60 & $120,8 \pm 23,9 \mathrm{a}^{*}$ \\
\hline 0
\end{tabular}

Médias com letras diferentes em cada tempo de experimento apresentam diferença significativa, $(\mathrm{P}<0,05)$, entre os grupos pelo teste $t$ não pareado, e o símbolo * apresenta diferença significativa, $(\mathrm{P}<0,05)$, ao longo do tempo, dentro dos grupos, pela análise de variância com pós-teste Tukey-Kramer.

Esses resultados mostram que a adição de semente de linhaça não contribuiu para a alteração do teor de colesterol, visto que não houve diferença significativa desse composto ao longo do experimento entre os grupos. O estudo realizado por Visentainer et al. (2005) mostra que adição de óleo de linhaça até 3,7\% parece baixar a concentração de colesterol nos filés de tilápias. Entretanto, Zelenka et al. (2003) não observaram alteração significativa no conteúdo de colesterol de truta arco-íris, com a adição de $2,5 \%$ e $5 \%$ de óleo de linhaça na dieta.

$\mathrm{Na}$ Tab. 5, apresenta-se a variação do peso do $M$. rosenbergii submetido aos diferentes tratamentos. Podem ser observados valores mais altos de peso no grupo-linhaça em relação ao grupo-controle $(\mathrm{P}<0,05)$ no final do experimento. Esses dados confirmam o potencial da ração de linhaça em aumentar a massa corporal do camarão ao longo do experimento.

O peso médio final, 1,38g, dos camarões do grupo-linhaça apresentou-se próximo ao citado por Correia et al. (2002), 1,41g, em juvenis com 63 dias de idade, alimentados por 42 dias com dieta à base de farinha de peixe e óleo de soja, e mais baixo que o encontrado por Correia et al. (1997), 1,80g, em camarões juvenis $M$. rosenbergii, alimentados por 70 dias com dieta à base de farinha de peixe e óleo de soja. Os resultados do presente estudo e os encontrados na literatura mostram que o peso corporal do camarão sofre influência tanto da qualidade da dieta quanto do tempo de duração do experimento.

Tabela 5. Peso corporal total dos camarões segundo os tratamentos e os tempos de avaliação (média e desvio-padrão)

\begin{tabular}{cc}
\hline Grupo - dia & Peso(g) \\
\hline Grupo-controle & $0,33 \pm 0,10^{*}$ \\
\hline 0 & $0,57 \pm 0,18 \mathrm{a}$ \\
60 & $0,77 \pm 0,55 \mathrm{a}$ \\
90 & $0,93 \pm 0,48 \mathrm{a}^{*}$ \\
Grupo-linhaça & $0,60 \pm 0,26 \mathrm{a}$ \\
30 & $0,78 \pm 0,43 \mathrm{a}$ \\
60 & $1,38 \pm 0,93 \mathrm{~b}^{*}$ \\
\hline
\end{tabular}

Médias com letras diferentes em cada tempo de experimento apresentam diferença significativa, $(\mathrm{P}<0,05)$, entre os grupos pelo teste $t$ não pareado, e o símbolo * apresenta diferença significativa, $(\mathrm{P}<0,05)$, ao longo do tempo, dentro dos grupos, pela análise de variância com pós-teste Tukey-Kramer.

Na Tab. 6, apresenta-se a relação de EPA, ácido araquidônico, colesterol, ácido linoleico sobre o ácido palmítico nos tecidos do camarão $M$. rosenbergii submetido aos tratamentos. Essa tabela apresenta uma relação qualitativa dos ácidos graxos e mostra a razão desses ácidos em relação ao ácido graxo saturado principal, o ácido palmítico. Essa relação é importante para analisar se a dieta-linhaça teve influência em modificar as concentrações desses ácidos nos tecidos dos camarões, principalmente em relação aos ácidos graxos poli-insaturados eicosapentaenóico e o linoleico.

Não houve modificação significativa na relação ácido eicosapentaenóico (EPA)/ácido palmítico, ácido araquidônico/palmítico e colesterol/palmítico entre os tratamentos. No grupo-controle, foi observado aumento significativo $(\mathrm{P}<0,05)$ da relação ácido linoleico/ácido palmítico $(1,47 \pm 0,22 ; 1,40 \pm 0,12$; $1,52 \pm 0,02$ ) durante todo o tratamento. O aumento na concentração do ácido linoleico pode repercutir em um balanceamento inadequado da relação $\omega-6 / \omega-3$. Esse resultado pode ser justificado pelo fato de a fonte de lipídeos da 
dieta se originar do óleo de soja, que, em sua composição, apresenta predominância do ácido linoleico, o que, consequentemente, refletiu na composição da ração e no perfil lipídico da carne do camarão. O grupo-linhaça apresentou valores baixos da relação ácido linoleico/ácido palmítico $(0,47 \pm 0,14 ; 0,35 \pm 0,12 ; 0,62 \pm 0,02) \quad$ (Tab. 6). Esses resultados enfatizam o potencial da linhaça em melhorar a relação $\omega-6 / \omega-3$ na carne do camarão.

Tabela 6. Relação do ácido eicosapentaenoico (EPA), ácido araquidônico, colesterol, ácido linoleico sobre o ácido palmítico (C16:0) dos camarões segundo os tratamentos e os tempos de avaliação (média e desvio-padrão)

\begin{tabular}{ccccc}
\hline Grupo - dia & EPA/C16:0 & Ác. araq./C16:0 & Ác. linoleico/C16:0 & Colesterol/C16:0 \\
\cline { 1 - 2 } Grupo- & & & & \\
controle & & & & \\
0 & $0,47 \pm 0,03$ & $0,16 \pm 0,02$ & $0,42 \pm 0,02$ & $0,19 \pm 0,09$ \\
30 & $0,13 \pm 0,06 \mathrm{a}$ & $0,052 \pm 0,02 \mathrm{a}$ & $1,47 \pm 0,22 \mathrm{a}$ & $0,08 \pm 0,10 \mathrm{a}$ \\
60 & $0,10 \pm 0,07$ & $0,05 \pm 0,02$ & $1,40 \pm 0,12 \mathrm{a}$ & $0,04 \pm 0,01$ \\
90 & $0,13 \pm 0,01 \mathrm{a}$ & $0,09 \pm 0,01 \mathrm{a}$ & $1,52 \pm 0,02 \mathrm{a}$ & $0,05 \pm 0,02 \mathrm{a}$ \\
Grupo- & & & & \\
linhaça & & & & \\
30 & $0,18 \pm 0,10 \mathrm{a}$ & $0,07 \pm 0,04 \mathrm{a}$ & $0,47 \pm 0,14 \mathrm{~b}$ & $0,08 \pm 0,04 \mathrm{a}$ \\
60 & - & $-\mathrm{nd}$ & $0,35 \pm 0,12 \mathrm{~b}$ & - nd \\
90 & $0,12 \pm 0,02 \mathrm{a}$ & $0,06 \pm 0,01 \mathrm{a}$ & $0,62 \pm 0,02 \mathrm{~b}$ & $0,04 \pm 0,00 \mathrm{a}$ \\
\hline
\end{tabular}

Médias com letras diferentes em cada tempo de experimento apresentam diferença significativa, $(\mathrm{P}<0,05)$, entre os grupos pelo teste $t$ não pareado. ${ }^{\text {nd }}$ Dados não detectados pela cromatografia.

Na Tab. 7, apresenta-se a razão da soma $(\Sigma) \omega-3$, $\omega-6$ e $\omega-9$ sobre o ácido palmítico dos camarões e a razão de $\omega 6 / \omega 3$ e dos ácidos graxos poliinsaturados sobre os ácidos graxos saturados. Não houve diferença significativa na soma do ômega-3 ( $\Sigma \omega$-3)/ácido palmítico durante todo o tratamento entre os grupos. Entretanto, a razão do $\Sigma \omega$-6/ácido palmítico apresentou diferença significativa durante todo o experimento com aumento significativo no grupo-controle em relação ao grupo-linhaça aos 90 dias de tratamento. Tal resultado justifica-se pelo fato de o ácido linoleico ser o ácido predominante na dieta-controle à base de óleo de soja. Esse comportamento dos ácidos graxos confirma os relatos de Visentainer et al. (2003) e Almeida e Bueno Franco (2006) de que a composição em ácidos graxos da dieta reflete diretamente na composição de ácidos graxos do animal.

A razão do $\Sigma \omega$-9/ácido palmítico apresentou-se mais elevada $(\mathrm{P}<0,05)$, durante todo $\mathrm{o}$ tratamento, no grupo-linhaça. Isso pode ser explicado pela presença de ácido oleico no óleo da farinha de linhaça, o que demonstra o potencial da linhaça no aumento da concentração de $\omega-9$ na carne do animal. Estudos evidenciam que a substituição de ácidos graxos saturados por ácidos graxos monoinsaturados, como o ácido oleico, na dieta diminui os teores de colesterol sérico, de LDL-colesterol e de triglicerídeos tanto quanto com o uso de ácidos graxos poliinsaturados. Em estudos epidemiológicos com população humana de países do Mediterrâneo, as dietas ricas em gorduras monoinsaturadas têm sido associadas a teores baixos de colesterol sanguíneo e menor incidência de doenças cardiovasculares (Mahan e Escott-Stump, 2003).

A relação $\omega-6 / \omega-3$ apresentou-se menor $(\mathrm{P}<0,05)$ aos 90 dias de tratamento no grupo-linhaça, sendo quase a metade do valor do grupocontrole. Esse resultado comprova que a utilização da linhaça como complemento na dieta melhora a relação $\omega-6 / \omega-3$ no tecido do camarão.

Resultado mais baixo foi reportado por Castell et al. (2004) em ouriço-do-mar (0,43) alimentado por quatro semanas com $5 \%$ de óleo de linhaça na dieta. Tidwell et al. (1998) mostraram que $M$. rosenbergii alimentado com dieta à base de soja durante três semanas apresentou relação de $\omega 6 / \omega 3(2,75)$ próxima ao resultado de 30 dias do grupo-linhaça. Querijero et al. (1997) verificaram relação de $\omega 6 / \omega 3$ de 3,4 em camarões $M$. rosenbergii alimentados durante 40 dias com dieta suplementada com $10 \mathrm{~g} / \mathrm{kg}$ de ácido oleico, $20 \mathrm{~g} / \mathrm{kg}$ de ácido linoleico e $2 \mathrm{~g} / \mathrm{kg}$ de ácido linolênico. 
Segundo Suárez-Mahecha et al. (2002), a relação adequada de $\omega 6 / \omega 3$ é de suma importância para a nutrição humana. $\mathrm{O}$ balanceamento inadequado pode acentuar um estado de deficiência do $\omega-3$. $\mathrm{O}$ ácido graxo $\alpha$-linolênico $(\mathrm{C} 18: 3, \omega-6)$ é convertido em EPA e DHA. Essa taxa de conversão é muito baixa em humanos e diminui cada vez mais se for aumentada a ingestão de ácido linoleico $(\omega-6)$, pois os dois substratos competem pelo mesmo sistema enzimático. O
Departamento de Saúde da Inglaterra (Department..., 1994) recomenda que o valor da relação $\omega 6 / \omega 3$ seja, no máximo, de 4 . A razão $\omega 6 / \omega 3$ foi menor, com diferença significativa $(\mathrm{P}<0,05)$ para o grupo-linhaça em relação $\mathrm{O}$ grupo-controle aos 90 dias. Esse fato evidência a contribuição da semente de linhaça na redução dos valores da razão $\omega 6 / \omega 3$ melhorando o valor nutricional da composição lipídica do camarão.

Tabela 7. Razão da $\Sigma \omega-3, \omega-6$ e $\omega-9$ sobre o ácido palmítico (C16:0) dos camarões e a razão de $\omega 6 / \omega 3$ e dos ácidos graxos poli-insaturados sobre os ácidos graxos saturados segundo os tratamentos e os tempos de avaliação (média e desvio-padrão)

\begin{tabular}{cccccc}
\hline $\begin{array}{c}\text { Grupo } \\
\text { dia }\end{array}$ & $\sum \omega 3 / \mathrm{C} 16: 0$ & $\sum \omega 6 / \mathrm{C} 16: 0$ & $\sum \omega 9 / \mathrm{C} 16: 0$ & $\omega 6 / \omega 3$ & $\begin{array}{c}\text { AGPI/ } \\
\text { AGS }\end{array}$ \\
\hline $\begin{array}{c}\text { Grupo- } \\
\text { controle }\end{array}$ & & & & & \\
0 & $0,60 \pm 0,06$ & $0,58 \pm 0,04$ & $1,15 \pm 0,01$ & $0,97 \pm 0,03$ & $0,73 \pm 0,03$ \\
& & & & \\
30 & $0,16 \pm 0,10 \mathrm{a}$ & $1,31 \pm 0,05 \mathrm{a}$ & $1,30 \pm 0,16 \mathrm{a}$ & $10,71 \pm 5,13 \mathrm{a}$ & $0,97 \pm 0,00 \mathrm{a}$ \\
60 & $0,23 \pm 0,11$ & $1,51 \pm 0,17 \mathrm{a}$ & $1,08 \pm 0,28 \mathrm{a}$ & $6,41 \pm 3,47$ & $0,80 \pm 0,26 \mathrm{a}$ \\
90 & $0,13 \pm 0,01 \mathrm{a}$ & $1,62 \pm 0,00 \mathrm{a}$ & $1,35 \pm 0,04 \mathrm{a}$ & $12,14 \pm 1,49 \mathrm{a}$ & $1,13 \pm 0,00 \mathrm{a}$ \\
Grupo- & & & & \\
linhaça & & & & & \\
30 & $0,42 \pm 0,23 \mathrm{a}$ & $0,49 \pm 0,17 \mathrm{~b}$ & $2,45 \pm 0,20 \mathrm{~b}$ & $1,72 \pm 0,98 \mathrm{a}$ & $0,44 \pm 0,09 \mathrm{~b}$ \\
60 & - nd & $0,35 \pm 0,11 \mathrm{~b}$ & $2,32 \pm 0,01 \mathrm{~b}$ & $-{ }^{n}$ & $0,57 \pm 0,41 \mathrm{~b}$ \\
90 & $0,12 \pm 0,02 \mathrm{a}$ & $0,83 \pm 0,01 \mathrm{~b}$ & $2,62 \pm 0,10 \mathrm{~b}$ & $7,14 \pm 0,57 \mathrm{~b}$ & $0,70 \pm 0,18 \mathrm{~b}$ \\
\hline
\end{tabular}

Médias com letras diferentes em cada tempo de experimento apresentam diferença significativa, $(\mathrm{P}<0,05)$, entre os grupos pelo teste $t$ não pareado. ${ }^{\text {nd }}$ Dados não detectados pela cromatografia.

A relação de ácidos graxos poli-insaturados sobre os ácidos graxos saturados (AGPI/AGS) foi mais baixa $(\mathrm{P}<0,05)$ no grupo-linhaça, durante todo o tratamento (Tab. 7). Os grupos apresentaram resultados mais baixos que os relatados por Visentainer et al. (2003) em tilápias-do-nilo (1,56) alimentadas durante 30 dias com dieta à base de óleos de girassol e linhaça, e reportados por Suárez-Mahecha et al. (2002) em camarão-d'água-doce (Penaeus monodon) $(1,63)$. O Departamento de Saúde da Inglaterra (Department..., 1994) argumenta que razões de AGPI/AGS menores que 0,45 indicam carnes pouco saudáveis, ou seja, alimentos com valores mais altos de AGPI/AGS indicam melhor valor nutricional. Ressalta-se que ambos os grupos, no presente trabalho, apresentaram, aos 90 dias de tratamento, adequada razão AGPI/AGS, acima do recomendado.
A dieta teste à base de linhaça contribuiu para o aumento da incorporação do ácido oleico (C18: $1, \omega-9)$ e melhorou a relação $\omega-6 / \omega-3$ na carne do camarão em relação ao grupo-controle. A razão de poli-insaturados/saturados dos grupos linhaça e controle, ao final do experimento, indicou que o camarão produzido com ambas as dietas apresentou-se como alimento saudável, em relação a este aspecto de sua composição.

\section{CONCLUSÕES}

A utilização da semente de linhaça como complemento da dieta de camarão-da-malásia influenciou no aumento da incorporação do ácido oleico $(\mathrm{C} 18: 1, \omega-9)$ e na melhora na relação $\omega$ -

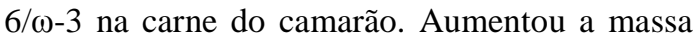
corporal do camarão e a concentração de proteína, melhorou o valor nutricional da carne do animal, sem modificar os teores de lipídeos totais e de colesterol. 


\section{REFERÊNCIAS}

ALMEIDA, N.M.; BUENO FRANCO, M.R. Influência da dieta alimentar na composição de ácidos graxos em pescado: aspectos nutricionais e benefícios à saúde humana. Rev. Inst. Adolfo Lutz, v.65, p.7-14, 2006.

ASSOCIATION of official analytical chemists. Official Methods of Analysis, 14 ed. Washington: AOAC, 1984.

ASSOCIATION of official analytical chemists. Official Methods of Analysis. 16 ed. Arlington: AOAC, 1995.

BLIGH, E.G.; DYER, W.J. A rapid method of total lipid extraction and purification. Can. J. Bioch., v.37, p.911-917,1959.

BRAGAGNOLO, N.; RODRIGUEZ-AMAYA, D.B. Otimização da determinação de colesterol por CLAE e teores de colesterol, lipídios totais e ácidos graxos em camarão rosa (Penaeus brasiliensis). Cienc. Tecnol. Aliment., v.17, p.275-280,1997.

BRAGAGNOLO, N.; RODRIGUEZ-AMAYA, D.B. Total lipid, cholesterol, and fatty acids of farmed freshwater prawn (Macrobrachium rosenbergii) and wild marine shrimp (Penaeus brasiliensis, Penaeus schimitti, Xiphopenaeus kroyeri); J. Food Composit. Anal., v.14, p.359369,2001

CASTELL, J.D.; KENNEDY, E.; ROBINSON, S.M.C. et al. Effect of dietary lipids on fatty acid composition and metabolism in juveline green sea urchins (Strongylocentrotus droebachiensis). Aquaculture, v.242, p.417-435, 2004.

CORREIA, E.S.; CASTRO, P.F.; FERREIRA, A.V. Avaliação de rações para o cultivo do camarão de água doce Macrobrachium rosenbergii em berçários. Bol. Inst. Pesca v.24, p.49-55, 1997.

CORREIA, E.S.; PEREIRA, J.A.; APOLINÁRIO, M.O. et al. Effect of pond aging on natural food availability and growth of the freshwater prawn Macrobrachium rosenbergii. Aquac. Eng., v.26, p.61-69, 2002.

DEPARTMENT of health. Nutritional aspects of cardiovascular disease. Report on health and social subjects, n.46 HMSO, London, 1994.
FURUYA, W.M.; HAYASHI, C.; SILVA, A.B.M. et al. Composição centesimal e perfil de ácidos graxos do camarão-d'água-doce. Rev. Bras. Zootec., v.35, supl., p.1577-1580, 2006.

HARTMAN, L.; LAGO, B.C.A. Rapid preparation of fatty acid methyl esters from lipids. Lab. Pract., v.22, p.475-477, 1973.

HAYASHI, C.; SOARES, C.M.; MATSUSHITA, M. et al. Desempenho e características de carcaça do escargot francês (Helix aspersa máxima) alimentados com rações contendo diferentes óleos vegetais. Cienc. Rural, v.34, p.231-237, 2004

HAYASHI, C.; SOARES, C.M.; MEURER, F. et al. Uso de diferentes óleos vegetais em dietas para a tilápia do Nilo (Oreochromis niloticus, L.), na fase inicial. In: REUNIÃO ANUAL DA SOCIEDADE BRASILEIRA DE ZOOTECNIA, 37., 2000, Porto Alegre. Anais... Porto Alegre: SBZ, 2000a. Disponível em: http //www. sbz.org.Br /scripts/anais 2000/index.asp. Acessado em:02/02/2009.

INSTITUTO Adolfo Lutz. Normas analíticas do Instituto Adolfo Lutz: métodos químicos e físicos para análise de alimentos. 3.ed. São Paulo: IAL, 1985. v.1, p.16-75, 245-246.

MAHAN, L.K.; ESCOTT-STUMP, S. Krause Alimentos, Nutrição e Dietoterapia. 10.ed., São Paulo: Roca, 2003. p.3, 30, 45, 46, 271,664, 940, 944.

MCKENZIE, D.J. Effects od dietary fatty acids on the respiratory and cardiovascular physiology of fish. Comparative Biochemistry and physiology, Oxford, v.128, p.607-621, 2001.

MENDEZ, M.H.M.; DERIVI, S.C.N.; RODRIGUEZ, M.C.R. et al. Método da fibra detergente neutro modificado para amostras ricas em amido. Cienc. Tecnol. Alim., v.5, p.123-131, 1985.

MOREIRA, A.B.; VISENTAINER, J.V.; SOUZA, N.E. et al. Fatty acids profile and cholesterol contents of three Brazillian brycon freshwater fishes. J. Food Composit. Anal., v.14, p.565-74, 2001.

PEDROSA, L.F.C.; COZZOLINO, S.M.F. Composição centesimal e de minerais de mariscos crus e cozidos da cidade de Natal/RN. Cienc. Tecnol. Aliment., v.21, p.154-157, 2001. 
QUERIJERO, B.V.L.; TESHIMA, S.; ISHIKAWA, M. et al. Utilization of monounsaturated fatty acid (18:1n-9, oleic acid) by freshwater prawn Macrobrachium rosenbergii (de Man) juveniles. Aquac. Nut., v.3, p.127-139, 1997.

SANTOS, F.L.; AZEREDO, V.B.; MARTINS, A.S.A. Efeito do fornecimento de ração complementada com semente de linhaça sobre os macronutrientes e colesterol em tecidos de camarões da Malásia (Macrobrachium rosenbergii). Cienc. Tecnol. Aliment., v.27, p.851-855, 2007.

SEBRAE/ES. 2005. Serviço de apoio às micro e pequenas empresas do Espírito Santo. Tecnologia de criação do camarão da Malásia (Macrobrachium rosenbergii) Manual de Carcinicultura de Água Doce. Centro de Tecnologia em Aquicultura e Meio Ambiente LTDA- CTA, Vitória, 2005.

SUÁREZ-MAHECHA，H.; FRANCISCO, A.; BEIRÃO, L.H. et al. Importância de ácidos graxos poliinsaturados presentes em peixes de cultivo e de ambiente natural para nutrição humana. Bol. Inst. Pesca, v.28, p.101-110, 2002.

TABELA brasileira de composição de alimentos - TACO versão 2, Núcleo de Estudos e Pesquisas em Alimentação (NEPA), Universidade Estadual de Campinas (Unicamp), Campinas, SP, 2006.

TIDWELL, J.H.; WEBSTER, C.D.; COYLE, S.D. et al. Fatty acid and amino acid composition of eggs, muscle and midgut glands of freshwater prawns, Macrobrachium rosenbergii(de Man), raised in fertilized ponds, unfertilized ponds or fed prepared diets. Aqua. Res., n.29, p.3745,1998

TURCHINI, G.M.; MENTASTI, T.; CAPRINO, F. et al. The relative absortion of fatty acids in brown trout (Salmo trutta) fed a commercial extruded pelletcoated with different lipid sources. Italian J. Anim. Sci., v.4, p.241-252, 2005.

VISENTAINER, J.V.; GOMES, S.T.M.; HAYASHI, C. et al. Efeito do tempo de fornecimento de ração suplementada com óleo de linhaça sobre a composição físico-química e de ácidos graxos em cabeças de tilápias do Nilo (Oreochromis niloticus). Cienc. Tecnol. Aliment., v.23, p.478-484, 2003

VISENTAINER, J.V.; HAYASHI, C.; SOARES, C.M. Quantificação de ácidos graxos ômega-3 (LNA, EPA e DHA), caracterização físicoquímica e composição de ácidos graxos em cabeças de tilápias jovens. In: CONGRESSO BRASILEIRO DE CIÊNCIA E TECNOLOGIA DE ALIMENTOS, 17., 2000, Fortaleza. Anais... Fortaleza: UFC/SBCTA, 2000. p.5221(Resumo).

VISENTAINER, J.V.; SALDANHA, T.; BRAGAGNOLO, N. et al. Relação entre teores de colesterol em filés de tilápias e níveis de óleo de linhaça na ração. Cienc. Tecnol. Alim., v.25, p.310-314, 2005a.

VISENTAINER, J.V.; SOUZA, N.E.; MAKOTO, M. et al. Influence of diets enriched with wax seed oil on the $\alpha$-linolenic, eicosapentaenoic and docosahexaenoic fatty acid in Nile tilapia (Oreochromis niloticus). Food Chem., v.90, p.557-560, 2005 b.

ZELENKA, J.; FAJMONOVÁ, E.; KOMPRDA, T. et al. Effect of dietary linseed and sunflower oil cholesterol and fatty acid contes in rainbow trout (Oncorhynchus mykiss) fillets. Czech J. Animal Sci., v.48, p.321-330, 2003.

ZENEBE, T.; AHLGREN, G.; GUSTAFSSON, I.B. Fatty acid and lipid content or Oreochromis niloticus L. in Ethiopian Lakes - dietary effects of phytoplankton. Ecology of Freshwater Fish. $J$. Fish Biol., v.7, p.146-58, 1998. 